\title{
Pressupostos teórico-metodológicos da genealogia: composições para um debate na educação
}

Andréa Braga Moruzzi

Doutoranda em Educação pela UFSCar Anete Abramowicz Doutora em Educação pela UFSCar e Professora da UFSCar

\section{Resumo}

Este trabalho procura mapear, a partir de um estudo bibliográfico, a genealogia enquanto referencial teórico metodológico pós-estruturalista. Como resultado, observa-se que a genealogia aparece de forma contínua e com muitas similaridades em Nietzsche, Foucault e Deleuze, contudo, na educação trata-se ainda de uma perspectiva teórica metodológica pouco explorada. São elementos da genealogia: questionar o conhecimento, o saber e as verdades; questionar quem as produzem e em que condições, fazendo emergir as relações de poder que as tornam possíveis; por fim, entrar no campo da genealogia é colocar em foco saberes antes não considerados, é trazer à tona o marginal e o impensado.

Palavras-chaves: Genealogia, Pós-Estruturalismo; Educação.

\section{Résumé}

Ce travail a comme objectif de cartographier, à partir d'une étude bibliographique, la généalogie en tant que référence théorico-méthodologique poststructuraliste. L'on a par conséquent observé que la généalogie apparait de façon continue et avec nombre de similitudes chez Nietzsche, Foucault et Deleuze. Toutefois, en éducation, il s'agit encore d'une perspective théorique peu exploitée. Font partie de la généalogie les éléments suivants : remettre en question la connaissance, le savoir et les vérités; s'intéresser à ceux qui les produisent et dans quelles conditions, mettant ainsi en lumière les rapports de pouvoir qui les rendent possibles; et, enfin, mettre en relief des savoirs auparavant non pris en compte, faire émerger le marginal et l'impensé.

Mots-clés: Généalogie; Poststructuralisme; Éducation. 


\section{Introdução - a genealogia como referencial teórico-metodológico}

genealogia vem sendo apontada como referencial teórico
metodológico em diversas áreas do conhecimento, a partir do
campo da filosofia. Influenciado pelo pensamento de Nietzsche, Foucault parece ter sido o pensador que mais utilizou e expandiu essa perspectiva teórica metodológica.

Como que num esforço conjunto, percebe-se que Nietzsche e posteriormente Foucault (re-significando a genealogia do seu antecessor) procuraram mostrar que a pesquisa genealógica não se trata de uma pesquisa de origem, retratando diversos pressupostos que ajudam a compreendê-la em outra dimensão. Partir em busca da origem é como se existisse algo de puro, de essencial, genético ou hereditário nos fatos e fenômenos a serem pesquisados. Na reconstrução da história a perspectiva genealógica aqui adotada compreende os fatos e as práticas vividas pelos indivíduos como construções sociais proferidas pelo saber, pelo poder e pelo sujeito, compondo diferentes modos de subjetivação, também por meio das práticas discursivas.

Compreende-se que a genealogia e os pressupostos que a embasa trazem importantes rupturas e direções para se pensar o referencial teóricometodológico em uma perspectiva pós-estruturalista. Deste modo, este artigo pretende, ainda de forma preliminar, ressaltar os pressupostos que embasam a genealogia, partindo inicialmente dos questionamentos e idéias lançadas por Nietzsche. Posteriormente pretende-se focar a genealogia em algumas importantes obras de Foucault. Por fim, procuramos elucidar como a genealogia aparece no campo da educação.

\section{As idéias impulsionadas por Nietzsche e a perspectiva genealógica}

A perspectiva teórica de Nietzsche é impulsionada por meio de questionamentos que colocavam sob suspeita o objetivismo e o universalismo do conhecimento produzido na modernidade. Essa suspeita se dá pela constatação feita pelo filósofo de que a ciência, cerne do 
conhecimento moderno, é constituída em sua base por elementos que não são verdadeiros. Em A gaia ciência, obra de 1882, Nietzsche escreveu que, em primeiro lugar, a ciência proclamava ser capaz de compreender a bondade e a sabedoria de Deus; em segundo, proclamava que conhecer mais, significaria ser melhor e mais feliz ${ }^{1}$; em terceiro, proclamava possuir algo de inofensivo, de neutro, e auto-suficiente, capaz de produzir apenas bons efeitos, controlando os maus impulsos do homem. Trata-se de proclamações equivocadas, segundo Nietzsche, à medida que, não é possível conhecer a mente de Deus por meio da natureza, pois Deus também é uma produção humana; "conhecer" não significa ser mais feliz e, por fim, não há neutralidade na ciência, à medida que quem a produz são os homens, dotados de suas crenças, valores e visões de mundo.

Tais pressupostos levaram Nietzsche a compreender que não existia uma verdade a ser perseguida e alcançada, mas uma série de concepções, múltiplos olhares que produzem uma série de saberes sobre determinado assunto, tema ou objeto. Entende-se que

[...] quanto maior for o número de afetos aos quais permitamos dizer sua palavra sobre uma coisa, quanto maior for o número de olhos, de olhos diferentes que saibamos empregar para ver uma mesma coisa, tanto mais completo será nosso conceito dela [...] (Nietszche, 1972, p.138-139).

Em outras palavras, reconhece-se positivamente a diversidade e a multiplicidade de saberes. Deste modo, está posto o desafio. Não existe um conhecimento universal produzido pelo homem, e nem o homem é tão onipotente $^{2}$. Essa compreensão trouxe para a filosofia de Nietzsche a denominação "filosofia perspectivista".

O projeto "perspectivista" de Nietzsche se consolida na fase final de sua produção, quando o filósofo lança, em 1887, a Genealogia da Moral' . A

\footnotetext{
${ }^{1}$ Entenda-se "por conhecer mais" adquirir os conhecimentos científicos.

${ }^{2}$ Ver Nietzsche. O nascimento da tragédia e acerca da verdade e da mentira, 1997.

${ }^{3}$ MARQUES, Antonio. A filosofia perspectivista de Nietzsche. 2003.

${ }^{4}$ Ver edição Nietzsche, 1972.
} 
concepção aqui apresentada traz como pressuposto que, desenvolver uma genealogia significa compor as múltiplas forças, vozes e olhares que construíram determinados saberes; trata-se de investigar e analisar quem teve o poder de falar sobre determinados saberes. Nietzsche principia esta concepção teórico-metodológica ao introduzir o conceito de valor nas ciências humanas. Assim, sobre determinados conceitos (valores) criados por uma sociedade, como por exemplo, o conceito de verdade, Nietzsche não questionava o que era verdade, como demais filósofos da época faziam, mas quem definiu verdade, como as pessoas se apropriavam desse valor e a quem o mesmo servia. Nietzsche compreendia que qualquer valor é engendrado por um tipo de vida, por isso o que se investigava sobre os valores não era o seu significado, mas quem os inventou, que tipo de vida inventa tais valores e que tipo de vida reproduz certos valores. $\mathrm{O}$ valor em si não existe, o que existe são valores engendrados, produzidos a partir de uma perspectiva. Dito de outra forma, não existe verdade, existem apropriações e significações sobre o que seja verdade a partir de certos modos de vida que se quer produzir e reproduzir. Assim, por exemplo, em Genealogia da Moral Nietzsche questiona como o ser humano se apropria do sentimento de culpa, traçando uma história da culpa, de suas apropriações e interiorizações pelos seres humanos. A culpa como algo material que foi interiorizada, culpa consigo mesmo e com a divindade. A genealogia consiste, portanto, em traçar a gênese de certo valor, e isto por sua vez, consiste em pensar quais forças estão agindo sobre certos valores.

Nas palavras de Nietzsche:

Este problema do valor da compaixão e da moral da compaixão (- eu sou um adversário do amolecimento moderno dos sentimentos -) à primeira vista parece ser algo isolado, uma interrogação à parte; mas quem neste ponto se detém, quem aqui aprende a questionar, a este sucederá o mesmo que ocorreu a mim - uma perspectiva imensa se abre para ele, uma nova possibilidade dele se apodera como uma vertigem, toda espécie de desconfiança, suspeita e temor salta adiante, cambaleia a crença na moral, em toda moral - por fim, uma nova exigência se faz ouvir, Enunciemo-la, esta nova exigência: necessitamos de uma crítica dos valores morais, o próprio valor desses valores deverá ser colocado em questão - para isto é necessário um conhecimento das condições e circunstâncias nas quais nasceram, sob as quais se desenvolveram e se modificaram (moral como 
conseqüência, como sintoma, máscara, tartufíceo, doença, mal-entendido; mas também moral como causa, medicamento, estimulante, inibição, veneno), um conhecimento tal como até hoje nunca existiu nem foi desejado. Tomava-se o valor desses "valores" como dado, como efetivo, como além de qualquer questionamento; até hoje não houve dúvida ou hesitação em atribuir ao "bom" valor mais elevado que ao "mau", mais elevado no sentido da promoção, utilidade, influência fecunda para o homem (não esquecendo o futuro do homem), E se o contrário fosse a verdade? E se no "bom" houvesse um sintoma regressivo, como um perigo, uma sedução, um veneno, um narcótico, mediante o qual o presente vivesse como que às expensas do futuro? Talvez de maneira mais cômoda, menos perigosa, mas também num estilo menor, mais baixo?... De modo que precisamente a moral seria culpada de que jamais se alcançasse o supremo brilho e potência do tipo homem? De modo que precisamente a moral seria o perigo entre os perigos? (Nietzsche, Frederich. 1972, p.3-4)

Os pressupostos da genealogia em Nietzsche, portanto, já apresentavam as seguintes discussões: primeiramente, não existe uma verdade, existem produções sobre a verdade e apropriações das mesmas; segundo, essas produções estão imbricadas nas relações de forças existentes em uma sociedade que faz um ou outro discurso ser considerado verdadeiro; terceiro, o olhar é sempre perspectivista; quarto, as verdades são construídas nas práticas sociais, portanto, isso significa se opor a idéia de que exista uma essência ou uma origem da verdade.

Esses pressupostos repercutem sobre Michel Foucault que passa a resignificar a genealogia de Nietzsche, como será explicitado a seguir.

\section{A genealogia - por Foucault}

Por que Nietzsche genealogista recusa, pelo menos em certas ocasiões, a pesquisa de origem (Ursprung)? Porque, primeiramente, a pesquisa, neste sentido, se esforça para recolher nela a essência exata da coisa, sua mais pura possibilidade, sua identidade cuidadosamente recolhida em si mesma, sua forma imóvel e anterior a tudo o que é externo, acidental, sucessivo. Procurar uma tal origem é tentar reencontrar "o que era imediatamente", o "aquilo mesmo" deu ma imagem exatamente adequada a si; é tomar por acidental todas as peripécias que puderam ter acontecido, todas as astúcias, todos os disfarces; é querer tirar todas as máscaras para desvelar enfim uma identidade primeira (Foucault, Michel, 1984. p.13).

Os pressupostos da genealogia perpassam por praticamente todos os trabalhos de Foucault. Há diferentes trabalhos nos quais a genealogia é apontada e desenvolvida como caminho metodológico. 
Em geral pode-se entender Foucault como um genealogista do poder, do saber e do sujeito, sendo que, em sua última fase Foucault aponta que seu objetivo, em todos os trabalhos, foi entender as formas pelas quais os indivíduos se tornam sujeitos.

Eu gostaria de dizer, antes de mais nada, qual foi o objetivo do meu trabalho nos últimos quase vinte anos. Não foi analisar o fenômeno do poder nem elaborar os fundamentos para tal análise. Meu objetivo, ao contrário, foi criar uma história dos diferentes modos pelos quais, em nossa cultura, os seres humanos tornam-se sujeitos (Foucault, Michel. In: Rabinon \& Dreyfus, 1995, p.231).

Deste modo, teria Foucault sido "apenas" um genealogista do sujeito, que analisou, para compreendê-lo, diferentes dispositivos como, por exemplo, o poder e o saber?

Sobre a genealogia de Nietzsche, fonte de inspiração para Foucault, o filósofo ressalta que não se pode compreender esta perspectiva teóricametodológica como uma busca pela origem (Ursprung) como acabou sendo compreendido por muitos autores. Em Gaia Ciência Nietzsche problematiza essa discussão tomando como foco a questão da poesia. Neste sentido afirma-se que não há uma origem da poesia, há somente uma invenção da poesia.

Um dia alguém teve a idéia bastante curiosa de utilizar um certo número de propriedades rítmicas ou musicais da linguagem para falar, para impor suas palavras, para estabelecer através de suas palavras uma certa relação de poder sobre os outros. Também a poesia foi inventada ou fabricada (Foucault, Michel, 1999a, p.6).

Como afirma Foucault essa discussão é bastante evidente em Genealogia da Moral onde, no final do primeiro discurso, Nietzsche faz referência a grande fábrica que produz os ideais humanos. Estes ideais não têm também uma origem, foram inventados e produzidos por uma série de "pequenos mecanismos". Neste sentido, ressalta como pressuposto da genealogia, a necessidade de se prestar atenção nesses pequenos mecanismos, não tendo medo da mesquinharia, “[...] pois foi de mesquinharia em mesquinharia, de pequena em pequena coisa, que finalmente as grandes coisas se formaram" (Foucault, Michel, 1999a, p.6). 
A essa ostentação à busca pela origem, é necessário se opor, com um bom método histórico, que preste atenção “[...] a pequenez meticulosa e inconfessável dessas fabricações, dessas invenções" (idem, ibidem). Esse método é a genealogia.

Compreende-se aqui que todo conhecimento fora também inventado e isso significa pressupor que ele não tenha uma origem ou uma essencialidade. De maneira mais precisa afirma-se que o conhecimento não está inscrito na natureza humana e que não constitui o mais remoto instinto do homem; não há na essência humana algo como um germe do conhecimento. Assim, Foucault afirma, por influência de Nietzsche, que “[...] o conhecimento é simplesmente o resultado do jogo, do afrontamento, da junção, da luta e do compromisso entre os instintos" (Foucault, 1999a, p.6).

Em Microfísica do poder também aparece a genealogia e Foucault a descreve:

Fazer genealogia dos valores, da moral, do ascetismo, do conhecimento não será, portanto, partir em busca da origem, negligenciando como inacessíveis todos os episódios da história; será ao contrário, se demorar nas meticulosidades e nos acasos dos começos; prestar uma atenção escrupulosa à sua derrisória maldade; esperar vê-los surgir, máscaras enfim retiradas, com o rosto do outro; não ter pudor de procurá-las lá onde elas estão, escavando basfon; deixar-lhes o tempo elevar-se no labirinto onde nenhuma verdade manteve jamais sob sua guarda (Foucault, 1984, p.11).

Em defesa da sociedade (1999b) Foucault irá localizar no século XVIII o processo político organizado pelo Estado para promover a ordenação dos saberes. Tal processo começa pela desqualificação e eliminação dos saberes considerados menores e inúteis; em seguida parte-se para a sua "normalização", tornando-os intercambiáveis; um terceiro momento é sua classificação e hierarquização. Por fim, centraliza-se o controle, a transmissão e a organização geral destes saberes. Está posto o que Foucault irá chamar de "sociedade disciplinar" ou, o nascimento das instituições, intercambiada pelas relações de "poder". Nas palavras do filósofo: 
O século XVIII foi o século do disciplinamento dos saberes, ou seja, a organização interna de cada saber como uma disciplina tendo, em seu campo próprio, a um só tempo, critérios de seleção que permitem descartar o falso saber, o não-saber, formas de normalização e de homogeneização dos conteúdos, formas de hierarquização e, enfim, uma organização interna de centralização desses saberes em torno de um tipo de axiomatização. [...] A ciência como domínio geral, como policiamento disciplinar dos saberes, tomou o lugar, tanto da filosofia quanto da mathesis (Foucault, 1999, p.217218).

Neste sentido Foucault define que a genealogia é um projeto de inserção de "saberes locais", "descontínuos" e "desqualificados", que tem por objetivo se opor ao pensamento unitário que se diz verdadeiro. Trata-se, portanto de uma "anticiências". Mas isso não significa que a genealogia reivindica o direito à ignorância e ao não saber, trata-se antes de tudo de uma “insurreição de saberes” (Foucault, 1999, p. 217-218).

A genealogia permite o questionamento e a percepção dos efeitos centralizadores de poder que vinculam os discursos científicos formulados em nossa sociedade e que fazem determinados saberes serem considerados e outros não, estabelecendo uma escala hierárquica e classificatória. Nesse sentido, a genealogia permite compreender porque em uma sociedade se considera um saber sobre o outro. Analisa-se assim, as condições de emergência de determinado saber em uma dada sociedade.

É possível ainda compreender, por meio deste trabalho, que:

A genealogia seria, pois, relativamente ao projeto de uma inserção dos saberes na hierarquia do poder próprio da ciência, uma espécie de empreendimento para dessujeitar os saberes históricos e torná-los livres, isto é, capazes de oposição e de luta contra a coerção de um discurso teórico unitário, formal e científico. A reativação dos saberes "menores" talvez dissesse Deleuze - contra a hierarquização científica do conhecimento e seus efeitos de poder intrínsecos, esse é o projeto dessas genealogias em desordem e picadinhas (Foucault, 1999b, p. 15-16).

Para Foucault (idem, ibidem), pode-se entender a arqueologia e a genealogia como partes de um mesmo projeto de insurreição de saberes. A arqueologia seria o método de análise das discursividades locais e a genealogia seria a própria tática interventora por meio da qual se desprendem os saberes "dessujeitados". 
Em outras palavras, podemos pensar nas analogias "arquivar" como método que busca mapear e levantar os dados, e depois traçar as gêneses, como método que busca encontrar as gerações de determinados temas/assuntos. Escavar e depois compreender as proveniências e seus efeitos, sendo que estas levam em conta os saberes não antes articulados, como fora dito, os saberes marginalizados por um certo tipo de conhecimento considerado verdadeiro.

$\mathrm{O}$ que parece interessante ressaltar é que, tanto a arqueologia quanto a genealogia partem, inicialmente, do entendimento de que todos os saberes são construídos e inventados por um. À maneira Nietzschiana, todos os conhecimentos são relações e jogos de poder e o que se questiona é: que tipo de valor ou valores, engendrado (s) em uma sociedade, constitui um ou outro saber como verdadeiros.

Um segundo aspecto é que, os valores, constituintes dessas "verdades", são materializados também nas práticas discursivas. Assim, para Foucault fica evidente que os sujeitos são constituídos pelas e nas práticas sociais nas quais decorrem inúmeras relações de poder, de saber, com diferentes modos de subjetivação. O sujeito é, pois, fruto das práticas sociais que se dão também por meio das práticas discursivas. E, portanto, são nessas práticas, discursivas ou não, que a genealogia atua ${ }^{5}$.

Recuperar ou fazer aparecer os saberes "rejeitados" é uma forma de entender e analisar os discursos e as práticas. Da mesma forma, investigar e compreender porque estes saberes "rejeitados" são excluídos é também uma forma de entender e analisar os discursos e as práticas. E por sua vez, analisar os discursos e as práticas é compreender a maneira pela qual os indivíduos são sujeitados na linguagem e fora dela.

\footnotetext{
${ }^{5}$ Foucault faz também considerações importantes sobre a análise do discurso (AD) quando está focado principalmente no movimento da arqueologia, cujo foco maior era somente nas práticas discursivas. Por ora, não será possível compreender essa discussão, mas de forma preliminar é possível entender que esta perspectiva atribui grande valor às práticas discursivas, pois é por meio delas que a realidade se manifesta e é também por meio dela que os sujeitos se constituem.
} 
Foucault afirma que

Em relação ao aspecto genealógico, este diz respeito à formação efectiva dos discursos, seja no interior dos limites do controlo, seja no exterior deles, seja, o mais das vezes, de um e de outro lado da delimitação (Foucault, 1971, p.18).

Sobre a arqueologia e a genealogia afirma que:

A bem dizer, estas duas tarefas não são nunca totalmente separáveis ; não há, de um lado, as formas de rejeição, de exclusão, de reagrupamento ou de atribuição ; e depois, do outro lado, num nível mais profundo, o brotar espontâneo dos discursos, que, imediatamente antes ou depois da sua manifestação, são submetidos à selecção e ao controlo (é o que sucede, por exemplo, quando uma disciplina ganha a forma e o estatuto de discurso científico) ; e inversamente, as figuras de controle podem formar-se no interior de uma formação discursiva (como a crítica literária enquanto discurso constitutivo do autor) : toda a tarefa crítica, interrogando as instâncias de controle, deve ao mesmo tempo analisar as regularidades discursivas por intermédio das quais aquelas se formam ; e toda a descrição genealógica deve ter em conta os limites actuantes nas formações reais. Entre a tarefa crítica e a tarefa genealógica, a diferença não está tanto no objecto ou no domínio, mas no ponto a atacar, na perspectiva e na delimitação (Foucault, 1971, p.18).

Também Deleuze (1976) traz algumas reflexões acerca da genealogia. Em Nietzsche e a Filosofia (1976, p.9) Deleuze define sobre o projeto genealógico de Nietzsche: "A história de uma coisa, em geral, é a sucessão das forças que dela se apoderam, e a coexistência das forças que lutam para dela se apoderar". Para este autor, na leitura que faz de Nietzsche:

Genealogia quer dizer simultaneamente valor de origem e origem dos valores. Genealogia opõe-se ao caráter absoluto assim como ao seu caráter relativo ou utilitário. Genealogia significa o elemento diferencial dos valores donde emana seu próprio valor. Genealogia quer dizer, portanto, origem ou nascimento, mas também diferença ou distanciamento na origem. Genealogia quer dizer nobreza e baixeza, nobreza e vileza, nobreza e decadência na origem (Deleuze, 1976, p.7).

Percebe-se neste sentido que há uma familiaridade entre os sentidos que se dá pra a genealogia. Estariam Foucault e Deleuze, entre outros, em uma mesma "ciranda teórica". Para Pelbart (1989) é interessante observar que: 
Foucault comenta Deleuze, que lê Blanchot, o qual se inspira em Foucault, que escreve sobre Klossowski, que influencia Deleuze. . . e assim por diante, para não falar em Derrida, Lyotard e tantos outros dessa mesma "família". Ciranda teórica, em que o dizer de um já é comentário sobre um outro e não pode ser entendido sem o eco suscitado em todos os demais. Infinito da interpretação, como uma genealogia talmúdica retorcida sobre si mesma num círculo vicioso simultâneo, da qual estivesse ausente aquilo que justamente jamais terá existido - o texto original (Pelbart, 1989, p.170).

Para usar uma expressão Deleuziana, podemos afirmar que Foucault e Deleuze, bem como Guattari ${ }^{6}$ são "intercessores” um do outro. Há, portanto, muita influência do pensamento de um sobre outro, colocando-os de certa maneira, dentro de uma mesma "família" de pensamento, como afirma Pelbarlt. Deleuze dizia que "[...] eu preciso dos meus intercessores para me exprimir, e eles jamais se exprimiriam sem mim: sempre se trabalha em vários, mesmo quando isso não se vê",7. Por esses motivos é difícil não perceber, em Deleuze a genealogia de Foucault e de Nietzsche.

\section{Genealogia e educação - reflexões preliminares}

Por essas breves composições do pensamento de Foucault sobre a genealogia podemos compreender que, tanto arqueologia e a genealogia são instrumentos pelos quais se efetivam as análises discursivas. Compreende-se aqui que o sujeito é constituído pelas práticas, onde se estabelecem inúmeras relações de poder, de saber e que são proferidas, também pelas e nas práticas discursivas. Investigá-la na perspectiva genealógica é, portanto, uma forma de entender os discursos que são considerados verdadeiros, bem como, entender porque são assim considerados. Trata-se de uma

\footnotetext{
${ }^{6}$ Félix Guattari trabalhou com Lacan, psicanalista da França na década de 70. O trabalho com Lacan é rompido e Guattari passa a trabalhar junto com Deleuze. O propósito maior de Guattari é entender as configurações sobre o desejo, os processos que constituem o desejo. Desenvolve junto com Rolnik (2005) uma metodologia de investigação chamada de "cartografias" do desejo. Essa metodologia influencia o trabalho de Deleuze e também o trabalho de alguns psicanalistas (ver Kastrup 2008). Junto com Deleuze, Guattari produz diversas obras, entre elas O anti-édipo (1972, primeira edição), Kafka - por uma literatura menor (1975), Rizoma (1976), Mil Platôs (1980), e O que é Filosofia (1991).

${ }^{7}$ Sabe-se que Deleuze e Guattari trabalharam juntos ao longo de muitos anos e que desenvolveram um método psicanalítico chamado esquizoanálise. Não vamos nos aprofundar neste trabalho, sobre essa questão. Neste momento nos interessa apenas a compreensão de Foucault e Deleuze sobre a genealogia.
} 
investigação que mapeia os discursos, situa-os e, ao mesmo tempo, analisa as relações de poder em determinada sociedade que faz com que certos discursos prevalecem e outros sejam apaziguados. Entende-se nesse sentido que toda sociedade engendra as práticas discursivas que lhes convém, de tal forma a organizar, selecionar, controlar e distribuir os discursos nelas proferidos, de acordo com os interesses emergentes do momento.

Por ora, pode-se compreender, portanto, que fazer genealogia (de forma inseparável a arqueologia) é propor uma metodologia investigativa que observa a descontinuidade, os acasos, os acontecimentos, as experiências, os intempestivos de tal forma que: investiga os ditos e os não ditos, fazendo emergir saberes soterrados pelas malhas do poder; busca compreender os motivos pelos quais certos discursos emergem e outros desaparecem, compondo toda trama discursiva de tal forma a compreendê-la dentro das relações de força; não procura partir em busca de uma origem ou de uma essência dos valores e das verdades proferidas nas práticas discursivas, mas procura compreender suas condições de emergência, suas transformações, suas apropriações naquilo que é dito ou não.

$\mathrm{Na}$ educação existe um amplo e complexo campo sobre o qual a perspectiva Foucaultiana vem emergindo, desde a década de 90. Deleuze e Guattari surgem no cenário educacional mais recentemente, principalmente a partir do início do século XXI. Utilizando-se desses referenciais teóricos, essas perspectivas, que também se inspiram nas idéias impulsionadas por Nietzsche, acabam recebendo diferentes denominações, como por exemplo, perspectivas pós-críticas, pós-estruturalistas, filosofia da diferença, pósmodernos, entre outras.

Neste complexo campo em que se expande as perspectivas pósestruturalistas em educação, utiliza-se os conceitos sobre o poder, sobre a verdade, sobre o sujeito (conceitos Foucaultianos), bem como outros conceitos criados por Deleuze e Guattari, como rizoma, sociedade do controle, acontecimentos, etc. Ou seja, há uma adesão para os pressupostos desenvolvidos por Foucault e Deleuze e Guattari. 
Contudo, percebe-se, ainda que de forma preliminar, que as tendências em educação que mencionam a genealogia como referencial teórico metodológico focam principalmente a Análise do Discurso de Foucault (AD). A genealogia surge como pressuposto e caminho investigativo para se analisar os discursos. Ela não aparece isoladamente. Compreende-se que os discursos são formas conjuntas de enunciados que se apóiam em uma mesma forma discursiva. Nesse sentido, é possível investigar, por meio da genealogia, os diferentes enunciados que formam determinados discursos pedagógicos, como por exemplo, discursos sobre a prática docente, discursos sobre a formação de professores, discursos sobre a diferença, discursos sobre a diversidade, discursos sobre a avaliação, discursos sobre a sexualidade, sobre a criança, sobre a infância, entre tantos outros que compõem os mosaicos saberes pedagógicos.

Por meio de um levantamento dos artigos que utilizavam a genealogia, encontramos, Fischer (2001). A autora traz essa discussão apontando que a genealogia é uma forma de fazer história, criada por Foucault, com o intuito de observar os corpos e as descontinuidades. Pois é nos corpos e nas suas não linearidades que estão inscritos a linguagem e as práticas discursivas ou não.

Assim, quando o arqueologista ressalta a dinâmica dos lados dedentro e de-fora dos discursos, de certo modo está afirmando sua vocação de genealogista: para ele, os sujeitos são efeitos de discursos, e esses efeitos, produzidos no interior de inúmeras e bem concretas relações institucionais, sociais e econômicas, não existem senão nos corpos: (Fisher, p.22).

\section{Algumas considerações sobre este artigo}

Neste trabalho procurou-se desenvolver uma composição da perspectiva genealógica, impulsionadas pelas idéias de Nietzsche e incorporada principalmente nas obras de Foucault. Percebeu-se a genealogia como pressuposto teórico metodológico em diversas obras do autor, desenvolvida e/ou comentada por ele. Na educação percebe-se que alguns autores que comentam a genealogia articulam-na com a Análise do Discurso 
de Foucault, embora possamos compreender que a genealogia não foca somente as práticas discursivas. São pressupostos da genealogia: oposição à pesquisa de origem; percepção perspectivista de fenômenos e fatos; observação dos discursos engendrados por uma determinada sociedade ou grupo; análise das condições que fazem emergir e prevalecer um ou outro discurso; percepção das relações de poder que estão em jogo nas práticas discursivas.

\section{Referências}

DELEUZE, Gilles. Nietasche e a Filosofia. Trad.: Edmundo Fernandes Dias e Ruth Joffily Dias, Rio de Janeiro: Editora Rio, 1976.

FAÉ, Reginaldo. A Genealogia Em Foucault. Psicologia Em Estudo. Maringá, V.9, N3, P. 409-416, Set/Dez De 2004.

FISCHER, Rosa Maria Bueno. Foucault e a análise do discurso em educação. Cadernos de Pesquisa, n. 114, npo. 1ve9m7-b2r2o3/,2 n0o0v1embro/ 2001

FOUCAULT, Michel, 1926-1984. A Verdade E As Formas Jurídicas. (Tradução Roberto Cabral De Meio Machado E Eduardo Jardim Morais, Supervisão Final Do Texto Léa Porto De Abreu Novaes) Rio De Janeiro: Nau Ed., 1999a.

FOUCAULT, Michel. Em Defesa Da Sociedade: Curso No College De France (1975-1976). São Paulo: Martins Fontes, 1999b.

FOUCAULT, Michel. O Sujeito e o Poder. In: RABINON, Paul \& DREYFUS, Hubert. Michel Foucault, uma Trajetória Filosófica: Para Além do estruturalismo e da hermenêutica, 1995.

MENEZES, Rodrigo Carqueja de. Devir e Agenciamento no pensamento de Gilles Deleuze. Comum - Rio De Janeiro - V.11 - No 26 - P. 66 A 85 - Janeiro / Junho 2006, P.6

NIETZSCHE, Frederich. A gaia ciência. Lisboa: Relógio D’Água, 1998a.

NIETZSCHE, Frederich. La genealogia de La moral. Madrid: Alianza, 1972

PELBART Peter Pál. Da clausura do fora ao fora da clausura - Loucura e desrazão. São Paulo: Editora Brasiliense, 1989. (1 Edição)

SCHOPKE, Regina. Por uma Filosofia da diferença: Gilles Deleuze, o pensador nômade. Rio de Janeiro: Contraponto; São Paulo: Edusp, 2004. 